\title{
Editorial: Ensuring a Vibrant Future for Research
}

\author{
Masood Zangeneh
}

Published online: 9 April 2009

(C) Springer Science + Business Media, LLC 2009

A recent budget passed by the conservative government in Canada introduced heavy slashand-burn budget cuts to research and development, jeopardizing Canada's role as a world leader in scientific research. This is unfortunate because such research can inform government policies in wide array of human service areas including Mental Health and Addiction services. Although sentiments seem to be shifting south of the border with the election of President Barack Obama (e.g. stem cell research), the Canadian government seems to be immune to such change. Unfortunately, this issue is not unique to Canada, as countries all over the world struggle to balance budgets amidst what has been called the biggest financial crisis since the great depression.

It is difficult to quantify the impact that cuts to research and development will have in the long term, and it is unclear which areas will feel these cuts the deepest. Often, it can take months, even years to feel the full force of such cuts, though it is certain that a lack of funding for research will ultimately weaken the body of knowledge produced in Canada, for as long as the funding crisis persists. As a consequence, this leaves the government officials who are responsible for service core funding and the allocation of funds to research and development with missed opportunities to implement evidence-based/informed social policies that deliver the greatest impact for the amount of money spent.

Because slash-and-burn budget cuts have undermined the future of research and development, it is now more important than ever to utilize our journal as a platform for burgeoning new research and networking platforms, in order to keep the debate surrounding best practices alive and well. The role academic journalism plays in developing a vibrant arena for such debate is very important. We need to create a stimulating multidisciplinary environment that encourages new ideas and mutual cooperation, all in a joint effort to find the most effective ways to address our most pressing mental health and addiction issues. This is vital if we want to arrive at a point where researchers, mental health professionals and public policy makers work together to find effective solutions that can have a meaningful impact on the lives of those who live with Mental Health and Addiction

M. Zangeneh $(\bowtie)$

International Journal of Mental Health \& Addiction (IJMA), Editorial Office, 54 Royal Chapin Crescent, Richmond Hill, ON L4S 2A7, Canada

e-mail: editor-in-chief@ijma-journal.com 
problems. We see vast potential in spearheading this expedition, and as such, we are making every effort to function as an incubator for groundbreaking ideas, innovative alternatives and the development of new and exciting research directions.

It is hoped that our current efforts are able to one day transform traditional models of service delivery and knowledge acquisition in the Mental Health and Addiction sector, allowing us to facilitate a fundamental shift in the way Mental Health and Addiction concepts and service models are understood and operationalized. With this in mind, it is our immediate goal to reach a global audience and to encourage ongoing discussion regarding Mental Health and Addiction issues. Failure to do so is short-sighted, as, research and development is the cornerstone to not only social progress, but to economic progress as well.

Masood Zangeneh

Editor-in-Chief

International Journal of Mental Health \& Addiction 